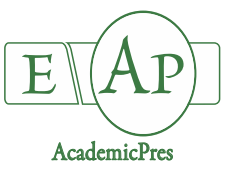

Gómez D et al. (2020)

Notulae Botanicae Horti Agrobotanici Cluj-Napoca 48(1):162-170

DOI:10.15835/nbha48111844

Research Article

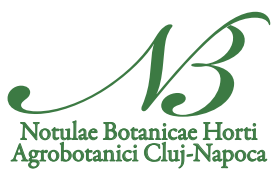

\title{
Assessing the effects of in vitro imposed water stress on pineapple growth in relation to biochemical stress indicators using polynomial regression analysis
}

\author{
Daviel GÓMEZ ${ }^{1}$, Doris ESCALANTE², Elliosha HAJARI ${ }^{3}$, \\ Oscar VICENTE ${ }^{4 *}$, SERSHEN ${ }^{5}$, José C. LORENZO² \\ ${ }^{1}$ Universidad de Concepción, Facultad de Ingenierí, Departamento de Ingeniería Quimica, Laboratorio de Carbo Cat, Región del Bio- \\ Bio, Chile; davielga26@gmail.com \\ ${ }^{2}$ University of Ciego de Avila, Bioplant Center, Laboratory for Plant Breeding and Conservation of Genetic Resources, Ciego de Avila, \\ 69450,Cuba; descalante@bioplantas.cu; jclorenzo@bioplantas.cu \\ ${ }^{3}$ Plant Improvement; Agricultural Research Council-Tropical and Subtropical Crops; Private Bag X11208, Nelspruit, 1200, South \\ Africa;HajariE@arc.agric.za \\ ${ }^{4}$ Universitat Politècnica de València, Institute for the Preservation and Improvement of Valencian Agrodiversity (COMAV), Valencia, \\ Spain; ovicente@upvnet.upv.es \\ ${ }^{5}$ University of the Western Cape, Department for Biodiversity and Conservation Biology, Bellville, 7535, \\ South Africa; sershenn@gmail.com
}

\begin{abstract}
Knowing the mechanisms that operate under water stress in commercial crops, particularly those that can affect productivity, such as phenolic or cell wall metabolism, is becoming increasingly important in a scenario of global climate change. However, our understanding of how to analyse statistically the relationships between these commonly used biochemical markers of water stress and growth in crops like pineapple, needs to be improved. In the present work, we have addressed the question of whether polynomial regression analysis can be used to describe the influence of selected plant metabolites (chlorophylls, carotenoids, phenolics and aldehydes) on shoot biomass, in response to a mannitol-induced water stress in temporary immersion bioreactors (TIBs). Polynomial regression analysis has been applied to investigate plant stress responses in many species but is very seldom used in in vitro screening studies. Here, the relationship between biochemical indicators ( $x$; independent variable) and shoot growth $(y$; dependent variable) has been characterised, with $y$ modelled as an $\mathrm{n}^{\text {th }}$ degree polynomial in $x$. This statistical approach accommodated for the non-linear (curvilinear) relationships between variables, and the results showed that shoot biomass was negatively, and significantly correlated with soluble phenolics, cell wall-linked phenolics and other aldehydes (characterised by "High" R² values).
\end{abstract}

Keywords: Ananas comosus (L.) Merr.; biostatistics; drought; in vitro osmotic stress; mannitol; plant metabolites; temporary immersion bioreactors (TIBs) 


\section{Introduction}

Statistical tools can outline trends in biological data sets. Regression analysis is used as a predictive tool to investigate the relationship between a dependent and an independent variable, with linear regressions being the most common type of analysis. However, when the collected data are non-linear (or curvilinear), polynomial regressions are performed. This is often the case for many biological processes in plants (see references below). For polynomial regressions, the relationship between the independent variable $x$ and the dependent variable $y$ is modelled as an $\mathrm{n}^{\text {th }}$ degree polynomial in $x$. In order to validate the strength of the model, the coefficient of determination is calculated. The coefficient of determination is the square of the correlation coefficient, also known as " $\mathrm{R}$ ". The $\mathrm{R}^{2}$ values range from 0 (indicating a poor fit) to 1 (indicative of the best fit, or relationship, between the two factors) (Ivanov, 1989).

Polynomial regression models have a wide range of applications and have been used in engineering, computer science, human resource management, urban planning, health sciences, and many other fields (Ivanov, 1989). In the context of plant sciences, polynomial regression analysis has been extensively applied in studies investigating the response of plants to varied stress conditions. Fernández et al. (2002) used polynomial adjustment of log-transformed data to show that water stress altered the developmental response of two desert grass species, with leaf area ratio being the most prominent factor affected. Similarly, Vieira et al. (2019) used polynomial regression analysis in modelling the gas exchange behaviour of melon exposed to water stress. Wijewardana et al. (2019) showed that polynomial regressions could be employed to model the germination of soybean seeds exposed to water stress. A novel application was described by Runeckles (1982), where polynomial regressions were applied to define the relative death rate of plants exposed to stresses. Polynomial regressions were also used to investigate the effect of sub-acute high temperature on ovule and pollen development in tomato (Peet et al., 1997), the effect of high temperature on photosynthetic processes in a forest ecosystem (Peet et al., 1997; Hüve et al., 2019), or to model the effect of excess ammonium fertiliser in tomato (Barker, 1999). However, to the best of our knowledge, there are no published reports on the use of polynomial regression analysis to identify suitable biochemical indicators of stress tolerance in in vitro screen systems such as Temporary Immersion Bioreactors (TIBs). Hence, the current study reports on the characterisation of pineapple plants responses to mannitol (to mimic water stress) in TIBs, in relation to established stress biomarkers, such as the levels of chlorophyll a and b, carotenoids, phenolics (soluble, cell walllinked and exuded into the medium) and aldehydes, and the fresh mass of the shoots produced. The empirical data used for the analyses emanates from a previously published study by our group (Gómez et al., 2017).

\section{Materials and Methods}

\section{Plant material and in vitro culture conditions}

Pineapple crowns were collected from plants grown in the field (cv. 'MD2') as per Daquinta and Benegas (1997). Upon receipt in the laboratory, the crown leaves were removed, and the stem was washed with detergent and tap water to remove soil and other particles. The crown stem was then decontaminated by immersion in $1 \%(\mathrm{w} / \mathrm{v})$ calcium hypochlorite for $10 \mathrm{~min}$. Axillary buds, including a portion of basal tissue, were excised and placed onto initiation medium. Explants were cultured in $300 \mathrm{ml}$ glass containers containing $5 \mathrm{ml}$ of liquid culture medium per explant. The culture medium was comprised of MS (Murashige and Skoog, 1962) salts, $100 \mathrm{mg} \mathrm{l}^{-1}$ myo-inositol, $0.1 \mathrm{mg} \mathrm{l}^{-1}$ thiamine- $\mathrm{HCl}, 30 \mathrm{~g} \mathrm{l}^{-1}$ sucrose, $4.4 \mu \mathrm{M}$ 6-benzyladenine (BA), and 5.3 $\mu \mathrm{M}$ naphthaleneacetic acid (NAA). After $45 \mathrm{~d}$ of growth, shoots were subcultured to promote multiplication of explants, in the same medium described above, except that it contained $9.3 \mu \mathrm{M}$ BA and $1.6 \mu \mathrm{M}$ NAA. Shoots were multiplied for six months, with plants being transferred to fresh medium every $45 \mathrm{~d}$. Once a sufficient number of shoots were obtained, they were placed in TIBs according to Escalona et al. (1999), supplemented 
with $3.0 \mu \mathrm{M}$ paclobutrazol. The TIBs were programmed to allow for immersion of plantlets into the culture medium for 2 min every $3 \mathrm{~h}$ for $30 \mathrm{~d}$. Each TIB contained $200 \mathrm{ml}$ of liquid medium with five explants per bioreactor.

Plants were exposed to varying levels of mannitol in $\operatorname{TIBs}(0,50,100,150$, and $200 \mathrm{mM})$. Each treatment was comprised of 3 bioreactors ( 5 explants per bioreactor). Cultures were maintained at $25 \pm 1{ }^{\circ} \mathrm{C} ; 80 \mu \mathrm{mol} \mathrm{m}$ ${ }^{2} s^{-1}$ with fluorescent light and an 8-hour photoperiod.

\section{Measurement of stress indicators}

Following 30 days of culture, shoot cluster fresh weight, and the levels of different biochemical stress markers were determined in the plant material. Total chlorophylls and carotenoids were extracted from plants with $5 \mathrm{ml}$ acetone $(80 \%, \mathrm{v} / \mathrm{v})$. The samples were then centrifuged $\left(12,000 \mathrm{rpm}\right.$ at $4{ }^{\circ} \mathrm{C}$ for $\left.15 \mathrm{~min}\right)$. The absorbance of the supernatant was measured at 646.6 and $663.6 \mathrm{~nm}$, and chlorophyll a and b contents were calculated as described in Porra (2002), whereas total carotenoid concentrations were determined from the absorbance of the samples at $470 \mathrm{~nm}$, according to the method of Lichtenthaler (1987). A colourimetric method based on the Folin Ciocalteu reagent was used for extraction and quantification of phenolics (Gurr et al., 1992), and the results were expressed as mg chlorogenic acid equivalents per $\mathrm{g}$ fresh weight. Malondialdehyde (MDA) and other aldehydes were quantified based on the reaction with thiobarbituric acid (Heath and Packer, 1968). Phenolics excreted into the medium were also determined, using a modification of the Hoagland (1990) procedure: $0.5 \mathrm{ml}$ of culture medium was mixed with $4.5 \mathrm{ml}$ of distilled water and $0.5 \mathrm{ml}$ of Folin Ciocalteau reagent $(50 \% \mathrm{v} / \mathrm{v})$. The mixture was stirred, the reaction was allowed to proceed for $5 \mathrm{~min}$ and $1 \mathrm{ml}$ of a saturated sodium carbonate solution was added. The mixture was stirred again, left for $60 \mathrm{~min}$, and the optical density was measured at $725 \mathrm{~nm}$. The concentration of phenolics was determined using a calibration curve with chlorogenic acid as the standard.

\section{Data analysis}

Polynomial regression analyses were performed using Microsoft Excel. Each polynomial regression involved 15 ( $x$, y) pairs (i.e. 5 mannitol concentrations; 3 TIBs per treatment). Determination coefficients $\left(R^{2}\right)$ obtained for $\mathrm{y}=\mathrm{ax}^{2}+\mathrm{bx}+\mathrm{c}$ used the shoot fresh weight as the dependent variable $(\mathrm{y})$, whereas biochemical indicators represented the independent variables $(\mathrm{x})$. The $\mathrm{R}^{2}$ values were classified as "Low" from 0.2184 to 0.3870 ; "Medium" from 0.3870 to 0.5556 ; and " High" from 0.5556 to 0.7243 . The following formula was used to define the three $\mathrm{R}^{2}$ categories: (Max $\mathrm{R}^{2}$ value observed - Min $\mathrm{R}^{2}$ value observed) / 3.

\section{Results and Discussion}

The current study investigated the application of polynomial regression analysis as a tool to define the response of pineapple plants to osmotic stress, applied in TIBs. The $\mathrm{R}^{2}$ value represents a numerical statistical index that describes the goodness of fit of a regression model. In the present work, $\mathrm{R}^{2}$ was used to indicate what fraction of $y$ variations occurred as a consequence of $x$ variations (Ivanov, 1989). Figure 1 shows the analysis and determination coefficient $\left(R^{2}\right)$ values corresponding to the independent variables chlorophyll a (panel $A$ ), chlorophyll b (B), carotenoids (C), soluble phenolics (D), and Figure 2 shows cell wall-linked phenolics (A), soluble phenolics in the culture medium (B), MDA (C) and other aldehydes (D). The results indicated that the soluble and cell wall-linked phenolics, and other aldehydes affected the changes in shoot biomass observed in response to osmotic stress (Figure 1D, Figure 2A, D). In this regard, $72.11 \%$ of the variations of pineapple shoot cluster fresh weight under mannitol stress correlated with changes in soluble phenolic levels $\left(R^{2}=0.7211\right.$; Figure 1D). The determination coefficient for this relationship was classified as "High". 

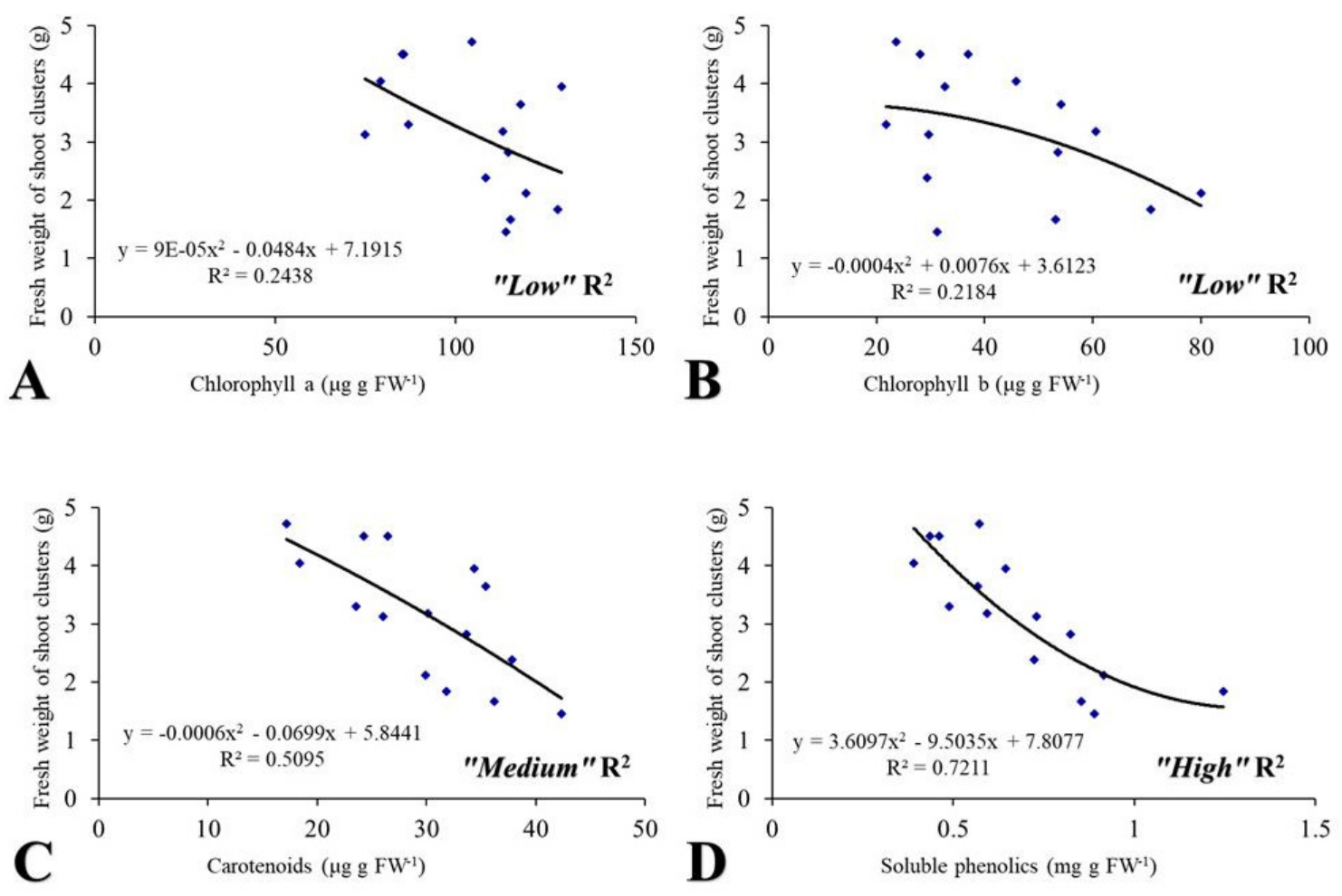

Figure 1. Determination coefficients $\left(\mathrm{R}^{2}\right)$ obtained in polynomial regressions analyses (Order $2: \mathrm{y}=\mathrm{ax}^{2}+$ $\mathrm{bx}+\mathrm{c}$; Microsoft Excel). The fresh weight of shoot clusters was the dependent variable (y), and chlorophyll a (A), chlorophyll b (B), carotenoids (C) and soluble phenolics (D), the independent variables. $\mathrm{R}^{2}$ were classified as "Low" from 0.2184 to 0.3870 ; "Medium" from 0.3870 to 0.5556 ; and "High" from 0.5556 to 0.7243

The results showed that as the soluble phenolic content of shoots increased, shoot weight declined, in agreement with the trend detected in the empirical data. A similar trend was observed for cell wall-linked phenolics and other aldehydes, i.e. as the levels of these two metabolites increased, shoot mass was adversely affected. These two factors also generated "High" $\mathrm{R}^{2}$ values: $68.17 \%$ of shoot cluster weight variations were explained by modifications of cell wall-linked phenolic contents (Figure $2 \mathrm{~A}$ ), and $72.43 \%$ by increases in the levels of other aldehydes (Figure 2D).

"Medium" $\mathrm{R}^{2}$ were recorded for carotenoid levels $\left(\mathrm{R}^{2}=50.95 \%\right.$, Figure $\left.1 \mathrm{C}\right)$ and MDA contents $\left(\mathrm{R}^{2}=\right.$ $51.61 \%$, Figure 2C). Changes in levels of chlorophylls a and b (Figure 1A, B), and soluble phenolics excreted into the culture medium (Figure 2B) did not appear to (mathematically) influence biomass of pineapple shoots in TIBs under osmotic stress, as the corresponding $\mathrm{R}^{2}$ values were classified as "Low".

From our previous work (Gómez et al., 2017), it was established that exposure of pineapple shoots to mannitol above $50 \mathrm{mM}$ for 30 days reduced the fresh weight of shoots with respect to the non-stressed controls; for example, the highest mannitol concentration tested $(200 \mathrm{mM})$ decreased the multiplication rate by $59.7 \%$ and cluster fresh weight by $59.8 \%$. From that study, several significant differences were found between the control and mannitol treatments using basic statistical analyses, namely one-way ANOVA and determination of 'overall coefficients of variation' (OCVs). 
166
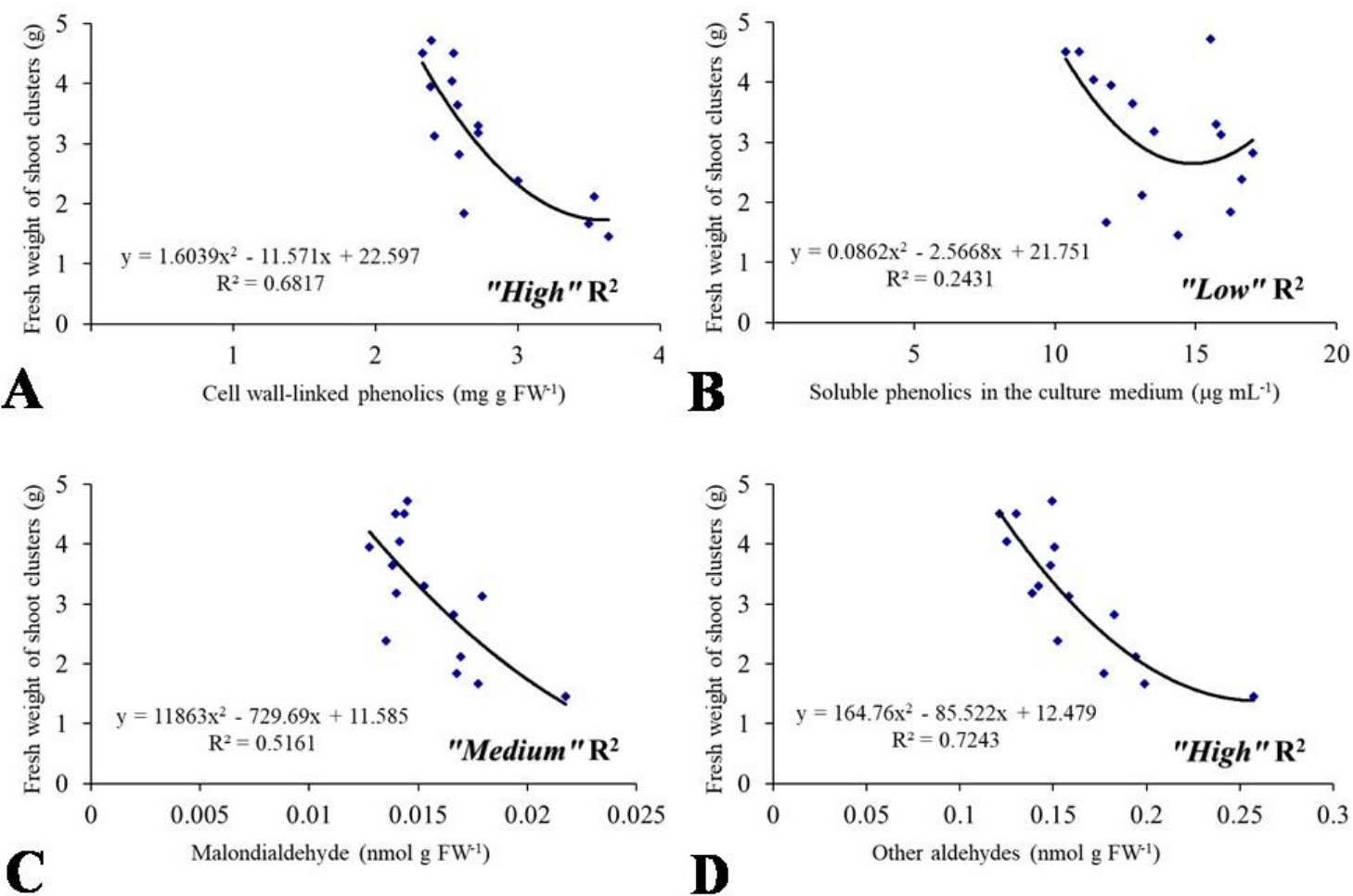

Figure 2. Determination coefficients $\left(\mathrm{R}^{2}\right)$ obtained in polynomial regressions analyses (Order $2: \mathrm{y}=\mathrm{ax}^{2}+$ $\mathrm{bx}+\mathrm{c}$; Microsoft Excel). The fresh weight of shoot clusters was the dependent variable (y), and cell walllinked phenolics (A), soluble phenolics in the culture medium (B), MDA (C) and other aldehydes (D), the independent variables. $\mathrm{R}^{2}$ were classified as "Low" from 0.2184 to 0.3870 ; "Medium" from 0.3870 to 0.5556 ; and "High" from 0.5556 to 0.7243.

Applying the more precise and robust polynomial regression analysis, those data have been reanalysed, which allowed refining the conclusions of the previous study. To give just some examples, both chlorophyll $b$ and shoot soluble phenolics contents increased in response to the osmotic stress applied; comparing the controls with the $200 \mathrm{mM}$ mannitol treatment, this increase amounted to 1.5 -fold for chlorophyll b contents (from 36.93 to $54.29 \mathrm{mg} \mathrm{g}^{-1}$ fresh weight), and to 2.1-fold for soluble phenolics (from 430.15 to $904.03 \mu \mathrm{g} \mathrm{g}^{-1}$ fresh weight). In both cases, the increments were statistically significant (one-way ANOVA, Tukey, $p>0.05$ ), with 'medium' OCVs (Gómez et al., 2017). However, polynomial regression analysis clearly distinguished the two putative stress indicators, ruling out the use of chlorophyll b (with a ' $L o w$ ' $\mathrm{R}^{2}$ value) as a reliable biochemical marker of osmotic stress in this specific experimental system, as compared to soluble phenolics, which showed a 'High' $\mathrm{R}^{2}$ value. Similarly, the significant increase in cell wall-linked phenolics and 'other aldehydes' in response to mannitol-induced osmotic stress, showing 'low' OCVs (Gómez et al., 2017), were nevertheless strongly correlated ('High' determination coefficients, $\mathrm{R}^{2}$ ) with the variations of pineapple shoot cluster fresh weight.

The impacts of climate change are already causing detrimental effects on agricultural productivity as well as in natural ecosystems. Warmer temperatures accompanied by longer dry spells and changing rainfall patterns affect all phases of plant development. Access to sufficient amounts of water (of good quality) at the appropriate developmental stage represents one of the most critical factors determining plant growth (Hernández et al., 2015; Naik and Al-Khayri, 2016).

Plants have evolved complex mechanisms to mitigate the adverse effects caused by drought, with a general reduction in growth being the typical response (Avramova et al., 2015). This could occur as a result of 
changes in $\mathrm{CO}_{2}$ assimilation (Gindaba et al., 2004) and effects on water relations, such as relative water content (Galle et al., 2007), leaf turgor pressure (Schachtman and Goodger, 2008) or osmotic potential (Silva et al., 2010). Accompanying these physiological changes, alterations in the concentration of specific plant metabolites with protective functions have been detected. Since salt stress includes an osmotic component, as water deficit, similar groups of metabolites are affected by drought and salinity, including carbohydrate levels, starch content (Chao et al., 2006; Zaher-Ara et al., 2016), sugars and oligosaccharides (Anderson and Kohorn, 2001), antioxidants and enzymes (Avramova et al., 2016; Avramova et al., 2017). In particular, several compounds with protective properties have been identified, including proline (AbdElgawad et al., 2015; ZaherAra et al., 2016), genkwanin (Awasthi et al., 2016), tanshinone IIA (Zaker et al., 2015), steviol glycosides (Gupta et al., 2015), myo-inositol (Díaz-López et al., 2012), glycine-betaine (Quan et al., 2004), anthocyanin (Awasthi et al., 2016), and abscisic acid (Gurmani et al., 2007).

From our previous work (Gómez et al., 2017) and the present analysis of pineapple plants micropropagated in TIBs, the levels of soluble phenolics and other aldehydes can be defined as the most precise biomarkers of mannitol-induced osmotic stress; these two groups of compounds are known to play a role in plant responses to stress conditions. These results are in agreement with other published reports of studies conducted in different culture systems and with different plant species (Winkel-Shirley, 2002; Haghighi et al., 2012; Rivelli et al., 2012; Selmar and Kleinwächter, 2013; Boestfleisch et al., 2014; Hernández et al., 2015; Boestfleisch and Papenbrock, 2017). This observation provides evidence indicating that TIBs, in combination with regression analyses of biochemical stress indicators, are suitable systems to investigate plant responses to stress conditions.

\section{Conclusions}

The current study supports the use of polynomial regression analysis for comparing the relative importance of biochemical indicators of stress tolerance in in vitro screening studies. We recommend that this statistical approach be applied to other species and stressors to validate its utility for screening varieties for stress tolerance in vitro.

\section{Authors' Contributions}

Conceptualization: OV, JCL; Data curation: DG, JCL; Formal analysis: JCL; Funding acquisition: OV, JCL; Investigation: DG, DE, JCL; Methodology: JCL; Project administration: JCL; Resources: OV, JCL; Supervision: EH, OV, S, JCL; Writing - original draft: DG, EH, OV, S, JCL; Writing - review and editing: OV. All authors read and approved the final manuscript.

\section{Acknowledgements}

This research received no specific grant from any funding agency in the public, commercial, or not-forprofit sectors. This research was supported by the Bioplant Centre (University of Ciego de Ávila, Cuba), the Universidad de Concepción (Chile), the Agricultural Research Council-Tropical and Subtropical Crops (South Africa), the Universitat Politècnica de València (Spain), and the South African Technology Network (South Africa). 


\section{Conflict of Interests}

The authors declare that there are no conflicts of interest related to this article

\section{References}

AbdElgawad H, De Vos D, Zinta G, Domagalska MA, Beemster GT, Asard H (2015). Grassland species differentially regulate proline concentrations under future climate conditions: an integrated biochemical and modelling approach. New Phytologist 208:354-369.

Anderson C, Kohorn B (2001). Inactivation of Arabidopsis SIP1 leads to reduced levels of sugars and drought tolerance. Journal of Plant Physiology 158:1215-1219.

Avramova V, AbdElgawad H, Zhang Z, Fotschki B, Casadevall R, Vergauwen L, Knapen D, Taleisnik E, Guisez Y, Asard H, Beemster GTS (2015). Drought induces distinct growth response, protection and recovery mechanisms in the maize leaf growth zone. Plant Physiology 169:1382-1396.

Avramova V, Nagel KA, AbdElgawad H, Bustos D, DuPlessis M, Fiorani F, Beemster GT (2016). Screening for drought tolerance of maize hybrids by multi-scale analysis of root and shoot traits at the seedling stage. Journal of Experimental Botany 67:2453-2466.

Avramova V, AbdElgawad H, Vasileva I, Petrova AS, Holek A, Mariën J, Beemster GT (2017). High antioxidant activity facilitates maintenance of cell division in leaves of drought tolerant maize hybrids. Frontiers in Plant Science 8:84.

Awasthi P, Gupta AP, Bedi YS, Vishwakarma RA, Gandhi SG (2016). Mannitol stress directs flavonoid metabolism toward synthesis of flavones via differential regulation of two cytochrome p450 monooxygenases in Coleus forskoblii. Frontiers in Plant Science 7:985.

Barker AV (1999). Foliar ammonium accumulation as an index of stress in plants. Communications in Soil Science and Plant Analysis 30:167-174.

Boestfleisch C, Wagenseil NB, Buhmann AK, Seal CE, Wade EM, Muscolo A, Papenbrock J (2014). Manipulating the antioxidant capacity of halophytes to increase their cultural and economic value through saline cultivation. Annals of Botany PLANTS 6:plu046. https://doi.org/10.1093/aobpla/plu046

Boestfleisch C, Papenbrock J (2017). Changes in secondary metabolites in the halophytic putative crop species Crithmum maritimum, Triglochin maritima and Halimione portulacoides as reaction to mild salt stress. PLoS ONE 12:e0176303. https://doi.org/10.1371/journal.pone.0176303

Chao SK, Kim JE, Jong AP, Eom TJ, Kim WT (2006). Constitutive expression of abiotic stress-inducible hot pepper $\mathrm{CaXTH} 3$, which encodes a xyloglucan endotransglycosylase/hydrolase homolog, improves drought and salt tolerance in transgenic Arabidopsis plants. FEBS Letters 580:3136-3144.

Daquinta M, Benegas R (1997). Brief review of tissue culture of pineapple. Pineapple News 3:7-9.

Díaz-López L, Gimeno V, Simón I, Martínez V, Rodríguez-Ortega W, García-Sánchez F (2012). Jatropha curcas seedlings show a water conservation strategy under drought conditions based on decreasing leaf growth and stomatal conductance. Agricultural Water Management 105:48-56.

Escalona M, Lorenzo JC, González B, Daquinta M, Borroto C, González JL, Desjardines Y (1999). Pineapple micropropagation in temporary immersion systems. Plant Cell Reports 18:743-748.

Fernández RJ, Wang M, Reynolds JF (2002). Do morphological changes mediate plant responses to water stress? A steady state experiment with two C4 grasses. New Phytologist 155:79-88.

Galle A, Haldimann P, Feller U (2007). Photosynthetic performance and water relations in young pubescent oak (Quercus pubescens) trees during drought stress and recovery. New Phytologist 174:799-810. 
Gindaba J, Rozanov A, Negash L (2004). Response of seedlings of two Eucalyptus and three deciduous tree species from Ethiopia to severe water stress. Forest Ecology and Managment 201:119-129.

Gómez D, Hernández L, Valle B, Martínez J, Cid M, Escalona M, Hernández M, Beemster GTS, Tebbe CC, Yabor L, Lorenzo JC (2017). Temporary immersion bioreactors (TIB) provide a versatile, cost-effective and reproducible in vitro analysis of the response of pineapple shoots to salinity and drought. Acta Physiologiae Plantarum 39:277.

Gupta P, Sharma S, Saxena S (2015). Biomass yield and steviol glycoside production in callus and suspension culture of Stevia rebaudiana treated with proline and polyethylene glycol. Applied Biochemistry and Biotechnology 176:863-874.

Gurmani AR, Bano A, Saleem M (2007). Effect of ABA and BA on growth and ion accumulation of wheat under salinity stress. Pakistan Journal of Botany 39:141-149.

Gurr S, McPherson J, Bowles D (1992). Lignin and associated phenolic acids in cell walls. In: Wilkinson DL (Ed). Molecular Plant Pathology. Oxford Press, Oxford, pp 51-56.

Haghighi Z, Modarresi M, Mollayi S (2012). Enhancement of compatible solute and secondary metabolites production in Plantago ovata Forsk. by salinity stress. Journal of Medical Plant Research 6:3495-3500.

Heath R, Packer J (1968). Photoperoxidation in isolated chloroplast: I. Kinetics and stoichiometry of fatty acid peroxidation. Archives of Biochemistry and Biophysics 125:189-198.

Hernández L, Loyola-González O, Valle B, Martínez J, Díaz-López L, Aragón C, Vicente O, Papenbrock J, Trethowan R, Yabor L, Lorenzo JC (2015). Identification of discriminant factors after exposure of maize and common bean plantlets to abiotic stresses. Notulae Botanicae Horti Agrobotanici ClujNapoca 43:589-598.

Hoagland RE (1990). Alternaria cassiae alters phenylpropanoid metabolism in Sicklepod (Casia obstusifolia). Journal of Phytopathology 130:177-187.

Hüve K, Bichele I, Kaldmäe H, Rasulov B, Valladares F, Niinemets Ü (2019). Responses of Aspen Leaves to Heatflecks: Both Damaging and Non-Damaging Rapid Temperature Excursions Reduce Photosynthesis. Plants 8:145.

Ivanov Z (1989). The Agricultural Experimentation Pueblo y Educación, Havana, pp 332.

Lichtenthaler HK (1987). Chlorophylls and carotenoids: pigments of photosynthetic biomembranes. Methods of Enzymology 148:350-382.

Murashige T, Skoog F (1962). A revised medium for rapid growth and bioassays with tobacco tissue culture. Physiologiae Plantarum 5:473-497.

Naik PM, Al-Khayri JM (2016). Abiotic and biotic elicitors-Role in secondary metabolites production through in vitro culture of medicinal plants. In: Shanker AK, Shanker C (Eds). Abiotic and Biotic Stress in Plants - Recent Advances and Future Perspectives. InTech, Al-Hassa, pp 247-277. http://dx.doi.org/10.5772/61442

Peet MM, Willits D, Gardner R (1997). Response of ovule development and post-pollen production processes in male-sterile tomatoes to chronic, sub-acute high temperature stress. Journal of Experimental Botany 48:101-111.

Porra R (2002). The chequered history of the development and use of simultaneous equations for the accurate determination of chlorophylls a and b. Photosynthesis Research 73:149-156.

Quan R, Shang M, Zhang H, Zhao Y, Zhang J (2004). Engineering of enhanced glycine betaine synthesis improves drought tolerance in maize. Plant Biotechnology Journal 2:477-486.

Rivelli A, De Maria S, Pizza S, Gherbina P (2012). Growth and physiological response of hydroponically grown sunflower as affected by salinity and magnesium levels. Journal of Plant Nutrition 33:1307-1323.

Runeckles V (1982). Relative death rate: a dynamic parameter describing plant response to stress. Journal of Applied Ecology 295-303.

Schachtman D, Goodger J (2008). Chemical root to shoot signaling under drought. Trends in Plant Science 13:281-287. 
170

Selmar D, Kleinwächter M (2013). Influencing the product quality by deliberately applying drought stress during the cultivation of medicinal plants. Indian Crops Production 42:558- 566.

Silva E, Ferreira-Silva S, Viegas R, Silveira J (2010). The role of organic and inorganic solutes in the osmotic adjustment of drought-stressed Jatropha curcas plants. Environmental and Experimental Botany 69:279-285.

Vieira DA, Mesquita AC, Marinho LB, Souza Vd, Aidar SdT, Carvalho MMP (2019). Gas exchanges of melon under water stress in the Submedium region of the São Francisco River Valley. Acta Scientiarum Agronomy 41. https://doi.org/10.4025/actasciagron.v41i1.42686

Wijewardana C, Alsajri FA, Reddy KR (2019). Soybean seed germination response to in vitro osmotic stress. Seed Technology 39:143-154.

Winkel-Shirley B (2002). Biosynthesis of flavonoids and effects of stress. Current Opinion in Plant Biology 5:218-223.

Zaher-Ara T, Boroomand N, Sadat-Hosseini M (2016). Physiological and morphological response to drought stress in seedlings of ten citrus. Trees 30:985-993.

Zaker A, Sykora C, Gössnitzer F, Abrishamchi P, Asili J, Mousavi SH, Wawrosch C (2015). Effects of some elicitors on tanshinone production in adventitious root cultures of Perovskia abrotanoides Karel. Indian Crops Production 67:97-102.
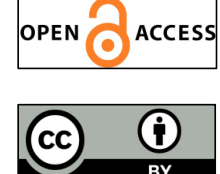

The journal offers free, immediate, and unrestricted access to peer-reviewed research and scholarly work. Users are allowed to read, download, copy, distribute, print, search, or link to the full texts of the articles, or use them for any other lawful purpose, without asking prior permission from the publisher or the author.

License - Articles published in Notulae Botanicae Horti Agrobotanici Cluj-Napoca are Open-Access, distributed under the terms and conditions of the Creative Commons Attribution (CC BY 4.0) License.

(c) Articles by the authors; UASVM, Cluj-Napoca, Romania. The journal allows the author(s) to hold the copyright/to retain publishing rights without restriction. 